\title{
LAB SCALE STUDY OF HRT AND OLR OPTIMIZATION IN A UASB TREATING SLAUGHTERHOUSE WASTEWATER
}

\author{
Martha N. Chollom ${ }^{1}$, Sudesh Rathilal ${ }^{2}$, Feroz M. Swalaha ${ }^{3}$, Babatunde F. Bakare ${ }^{4}$, \\ Emmanuel Kweinor Tetteh
}

\begin{abstract}
As the quality of most water sources and the environment continue to deteriorate, the public is increasingly concerned about the issues of sustainability. To combat this, strict policies and legislations are being placed to enable the treatment of wastewaters before discharging and possibly reusing it. Animal slaughterhouses have proven to be important sources of wastewater with high levels of organics such as chemical oxygen demand (COD), biological oxygen demand (BOD), total suspended solids (TSS), volatile suspended solids (VSS), fats and proteins. Discharging wastewater without any form of treatment into receiving water bodies has shown to contaminant water sources and as well to be detrimental to aquatic animals. Anaerobic processes have been proposed as a good alternative for the treatment of wastewaters with high or medium organic loads. The production of biogas through anaerobic digestion offers substantial advantages over other biological methods of waste treatment. The aim of this study was to elucidate the effect of process operational parameters on the performance of an up-flow anaerobic sludge blanket reactor (UASB). The reactor was used for the treatment of a synthetic wastewater which was synthesised to emulate that obtainable from a slaughterhouse. Organic loading rate (OLR) was increased by varying the hydraulic retention times (HRT) from 8-16 hours. The temperature of the reactor was maintained at a constant $35^{\circ} \mathrm{C}$ while the $\mathrm{pH}$ was varied from 6.5 to 7.5 . The result of the work indicated an optimum OLR of $4.5-7.5 \mathrm{kgCOD} \cdot \mathrm{m}^{-3} \cdot \mathrm{d}^{-1}$ and an optimum COD of 75-86\%. Similarly, a biogas yield of $2850 \mathrm{ml} /$ day was found to be the highest at a HRT of 12 hours at the optimum OLR. At the highest OLR, flotation occurred and consequently the active biomass was washed out from the reactor. The results indicated that anaerobic treatment systems are applicable to the treatment of wastewaters with high levels of organics.
\end{abstract}

UDC classification: 502/504; DOI: http://dx.doi.org/10.12955/cbup.v6.1290

Keywords: Anaerobic digestion, hydraulic retention times, organic loading rate, chemical oxygen demand, slaughterhouse wastewaters, biogas

\section{Introduction}

Most quality water sources continue to deteriorate with the public concerned with the issues of water's sustainability. To combat this, strict policies and legislations are being introduced to ensure that wastewaters are treated before being discharged and also the reuse of treated effluent is encouraged to be considered industries (Chollom et al., 2015; Tetteh et al., 2017; Dasgupta et al., 2015). Animal slaughterhouses have proven to be important sources of wastewater with high levels of organics such as chemical oxygen demand (COD), biological oxygen demand (BOD), total suspended solids (TSS), volatile suspended solids (VSS), fats and proteins. These characteristics of high levels of organics associated with slaughterhouse wastewater proves that it is much polluted. Therefore, discharging slaughterhouse wastewater without any form of treatment into receiving water bodies has shown to contaminate freshwater sources and are thus is detrimental to the environment and human health ( Bustillo-Lecompte \& Mehrvar, 2015; Bustillo-Lecompte \& Mehrvar, 2017).

slaughterhouse wastewater is said to consume large volumes of water, Bustillo-Lecompte \& Mehrvar, (2017) and Gerbens-Leenes et al., (2013) in their study indicated that about $24 \%$ of the total freshwater in the food and beverage industry is consumed by the meat producing industry. This huge consumption of water is from the various processes that occur during the slaughtering of animals and cleaning of the slaughterhouse facilities, meat processing plants and other housekeeping (Bustillo-Lecompte \& Mehrvar, 2017; Chollom et al., 2015). Due to different practices, a wide variation in the slaughterhouse wastewater composition is usually observed.

\footnotetext{
${ }^{1}$ Faculty of Engineering and the Built Environment, Department of Chemical Engineering, Durban University of Technology, South Africa, mnchollom@gmail.com

${ }^{2}$ Faculty of Engineering and the Built Environment, Department of Chemical Engineering, Durban University of Technology, South Africa, rathilals@dut.ac.za

${ }^{3}$ Faculty of Applied science, Department of Biotechnology and Food Technology, Durban University of

Technology, South Africa, fswalaha@dut.ac.za

${ }^{4}$ Faculty of Engineering, Department of Chemical Engineering, Mangosuthu University of Technology, South Africa, bfemi@mut.ac.za

${ }^{5}$ Faculty of Engineering and the Built Environment, Department of Chemical Engineering, Durban University of Technology, South Africa, ektetteh34@gmail.com
} 
Treatment of slaughterhouse wastewater is similar to those employed in conventional treatment plants treating other wastewaters. Techniques such as preliminary, primary, secondary, and even tertiary treatment are employed ( Bustillo-Lecompte \& Mehrvar, 2017; Gerbens-Leenes et al., 2013). Chemical, biological or advanced treatment and so on could be categorised into one of the above classifications. Biological systems have been used for the degradation of slaughterhouse wastewaters (BustilloLecompte \& Mehrvar, 2015). Anaerobic digestion which is a biological treatment method and has the advantage of degrading these contaminants and subsequently producing biogas. The anaerobic digestion process is reliable in wastewater and waste treatment, energy production, pollution reduction, and organic solid waste management in the agricultural field, as a being a well-established technology with environmental benefits (Gerbens-Leenes et al., 2013).

However, the complexity of the anaerobic digestion process is due to the fact that it involves the use of different bacteria and methanogenic archaea to decompose organic matter, thereby producing valuable biogases such as methane $\left(\mathrm{CH}_{4}\right)$ which can be converted into electricity (Kweinor Tetteh et al., 2017; Bustillo-Lecompte \& Mehrvar, 2017). Different configurations have been used for anaerobic digestion (AD) processes. The choice of the configuration to use will be based on the type of wastewater and its complexity (Kweinor Tetteh et al., 2017). Some examples of these biological configurations include the anaerobic batch reactor (Bustillo-Lecompte \& Mehrvar, 2017), the dissolved air flotation (DAF)-up flow anaerobic sludge blanket (USAB) ( Tetteh et al., 2017), USAB-Coagulation-flocculation, the anaerobic fixed film reactor, the membrane bioreactor, the sequencing batch reactor (SBR), and the anaerobic-anoxic-aerobic reactor. The UASB has been proposed as a good alternative for the treatment of wastewaters with high or medium organic loading rates (OLR) at varying hydraulic retention times (HRT), low energy input and low space conservation (Lettinga \& Pol, 1991;Torkian et al., 2003).

Despite the advantages offered by the UASB process, its major limitation is its complexity, operational instability, changes in environmental conditions such as temperature and $\mathrm{pH}$. These disadvantages have caused an interest in the optimization of the UASB process conditions for the optimal efficiencies of anaerobic processes. In this context, this study aimed to shed light onto the effect of changing the HRT, $\mathrm{pH}$ and OLR on the production of biogas and COD reduction, by defining their optimum settings levels to enhance anaerobic digestion performance.

\section{Materials and methods}

\section{Synthetic slaughterhouse wastewater}

Synthetic slaughterhouse wastewater emulating that from the slaughterhouse wastewater was prepared before each experimental run. This consisted of distilled water, peptone, glucose, commercial meat powder, sodium chloride, potassium dihydrogen orthophosphate, calcium chloride, magnesium sulphate, cupper chloride, urea, and sodium bicarbonate supplied by Sigma Aldrich. The synthetic slaughterhouse wastewater used specifications from Kweinor Tetteh et al., (2017) and Lettinga \& Pol, (1991), with a BOD/COD ratio of $0.40-0.53$ as compared with real slaughterhouse wastewater.

Seed and experimental setup

The UASB reactor used for the experiment was constructed from Plexiglas glass with a working volume of $4.5 \mathrm{~L}$ and the use of peristaltic pump (MODEL). The UASB was continuously fed with synthetic slaughterhouse wastewater at the bottom of the reactor and the effluent was collected at the top. It was operated at a constant mesophilic temperature of $35 \pm 1{ }^{\circ} \mathrm{C}$ with three different levels of OLR $(2,6$ and $\left.10 \mathrm{kgCOD} \cdot \mathrm{m}^{-3} \cdot \mathrm{d}^{-1}\right)$, HRT $(6,12$ and 18 hours) and $\mathrm{pH}(6,7$ and 8$)$. The reactor was started with a TSS of $19.4 \mathrm{~g} / \mathrm{L}$ and a VSS of $13.8 \mathrm{~g} / \mathrm{L}$ and digested the seed sludge collected from a local South Africa slaughterhouse wastewater treatment plant. This was operated at an OLR of $1.54 \mathrm{kgCOD} \cdot \mathrm{m}^{-3} \cdot \mathrm{d}^{-1}$ and a HRT of 24 hours for 5 days. The OLR was then increased stepwise according to the chosen HRT and it was maintained to enable the microorganisms to adopt to the new loadings until the system had attained stability. Each condition was operated at a constant solid retention time (SRT) of 15 days before changing to the next condition. The $\mathrm{pH}$ of the reactors was maintained through additions of $1 \mathrm{M}$ of $\mathrm{HCl}$ or $\mathrm{NaOH}$ (Bustillo-Lecompte \& Mehrvar, 2017; Kweinor Tetteh et al., 2017).

Analytical methods

A water displacement technique was used to measure the biogas that evolved from the AD process (Jha et al., 2017). COD which is measured based on the quantity of oxidant $\left(\mathrm{Cr}^{+6}\right)$ consumed was expressed in terms of its oxygen equivalence and was determined using close refluxing according to the standard 
method 5220D (Chollom et al., 2015). The pH, VSS and TSS were determined according to the APHA Standard Methods (APHA/AWWA/WEF, 2012). The initial COD for the runs phases 1, 2 and 3 was 1499,2139 and $3051 \mathrm{mg} / \mathrm{L}$ respectively.

Results and Discussion

The responses of biogas, COD and alkalinity were used to define the performance settings of the AD process operating conditions. In this study, the performance indicators were evaluated as the response to the input variables OLR, HRT and $\mathrm{pH}$ operated at three different settings levels. Although, it has been mentioned that the $\mathrm{AD}$ process performance can be influenced by many factors, herein, it was determined that an increase in the OLR had a significant effect on the biogas production and COD reduction.

Comparing the performance of the AD process with regards to the effects of OLR, HRT and $\mathrm{pH}$, similar trend was observed for the variables considered. This was due to the fact that the VSS and COD introduced affected the $\mathrm{AD}$ performance (biogas rate and $\mathrm{COD}$ reduction). On the introduction of a new COD or condition to the reactor, an increase or decrease in the biogas resulted. In addition, the methanogens need time to digest before it can release the biogas (Bustillo-Lecompte \& Mehrvar, 2017; Gerbens-Leenes et al., 2013).

Effects of OLR on biogas production and COD reduction

In reference to the aim of this study, the enhancement of biogas production with respect to an increase in OLR was evaluated. The experiment was carried out for a period of 50 days, and the biogas production and COD reduction was measured daily. The results show that the biogas production rate appeared the highest on the $5^{\text {th }}$ day $(8000 \mathrm{ml} /$ day $)$, then with the introduction of the new OLR rate an inhibition was observed which led to a drop in the production of biogas until the microbial community later on adapted to the new environment. A lower production rate $(4000 \mathrm{ml} /$ day $)$ was then obtained on the $20^{\text {th }}$ day. In the second phase, there was a sharp rise from $3500 \mathrm{ml} /$ day $\left(22^{\text {nd }}\right.$ day) of biogas to 8500 $\mathrm{ml} /$ day ( $30^{\text {th }}$ day), and then a rapid drop in biogas production was observed, even after the introduction of the third phase of OLR of $10 \mathrm{kgCOD} \cdot \mathrm{m}^{-3} \cdot \mathrm{d}^{-1}$ until the study was over on the $50^{\text {th }}$ day. The biogas production and COD reduction at different OLR is depicted in Figure 1.

The average daily biogas production obtained at 3 and $7 \mathrm{kgCOD} \cdot \mathrm{m}^{-3} \cdot \mathrm{d}^{-1}$ were 4944 and $6359 \mathrm{ml} / \mathrm{d}$ respectively, whereas a further increase in OLR of $10 \mathrm{kgCOD} \cdot \mathrm{m}^{-3} \cdot \mathrm{d}^{-1}$ decreased the biogas production rate to $4803 \mathrm{ml} / \mathrm{d}$. However, the OLR profile increased slightly with $60-70 \%$ of COD removal performance during the start-up phase of OLR of $3 \mathrm{kgCOD} \cdot \mathrm{m}^{-3} \cdot \mathrm{d}^{-1}$, then there was an increase of 85$90 \%$ for the second phase of $7 \mathrm{kgCOD} \cdot \mathrm{m}^{-3} \cdot \mathrm{d}^{-1}$. At the last phase, the COD removal performance of the $10 \mathrm{kgCOD} \cdot \mathrm{m}^{-3} \cdot \mathrm{d}^{-1}$ decreased to $75-80 \%$. This is due to the microbial community been less than the organic matter presence. Thus, the food nutrients available are greater than the microorganism, resulting in some of the organic matter not degraded in the effluent. This might also be due technical failures and under/overfeeding to the digester (Gerbens-Leenes et al., 2013).

Effects of HRT on biogas production and COD reduction

The effects of HRT was investigated in order to avoid microbial growth limitations and the anaerobic digestion performance as depicted in Figure 2. It was found that as the HRT was kept for a longer period the more biogas was produced. The OLR and HRT of USAB operation has a significant impact on the efficiency of biogas production. The biogas produced with HRT of 6,12 and $18 \mathrm{~h}$, from 6024 $\mathrm{ml} / \mathrm{d}, 6864 \mathrm{ml} / \mathrm{d}$ and $4944 \mathrm{ml} / \mathrm{d}$ respectively were produced for each phase of the HRT. Likewise, the COD removal recorded for HRT 6, 12 and $18 \mathrm{~h}$ were $76.7 \%, 90.3 \%$ and $61.3 \%$ respectively. Generally, the methanogens required a long regeneration period, as compared with the hydrolysis-acidogens bacteria. Usually, the HRT is required to be long enough in order to avoid the washing out of the microorganisms from the reactor. Thus ensuring the retention of the methanogens, which might prolong the study. Correspondingly, to this study, an HRT at $18 \mathrm{~h}$ recorded lower amounts of biogas and COD removal. This might be due to insufficient amounts of nutrients to nourish and withstand the microbial community during that long period to enhance the biogas production and COD removal (Lettinga \& Pol, 1991; Torkian et al., 2003). 

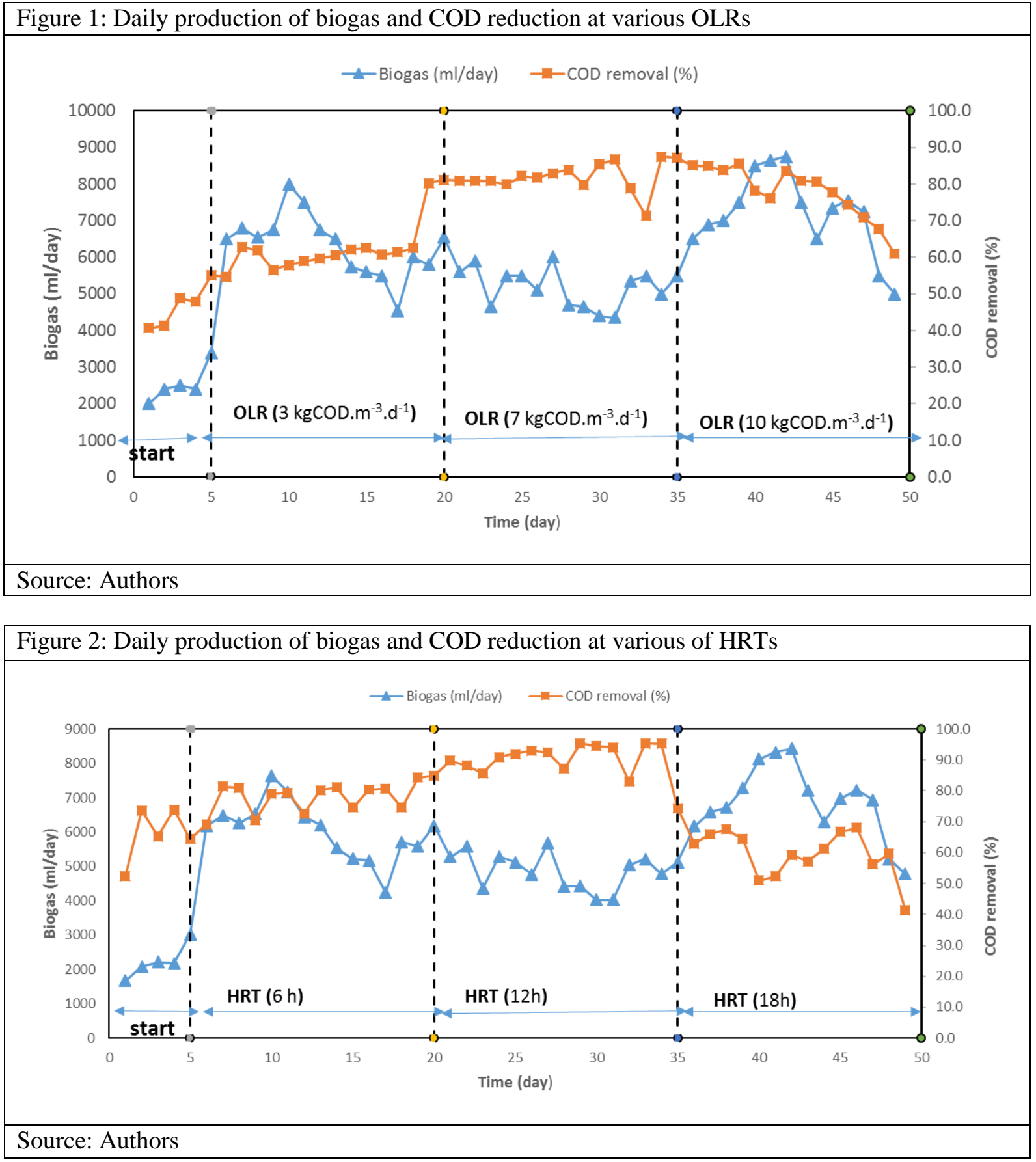

\section{Effects of $\mathrm{pH}$ and alkalinity on the AD performance}

The control of $\mathrm{pH}$ is one of the key environmental factors that have great influence on biogas production. The $\mathrm{AD}$ process is extremely vulnerable to $\mathrm{pH}$, such that an inhibition of methanogens occurs when the $\mathrm{pH}$ drop below 6.8 or exceeds 7.2. However, the methanogens can still degrade the contaminants in a suitable acidity while excessive alkalinity inhibits and disintegrates the microbial community and results in the subsequent failure of the AD process. Therefore, a buffer was dosed to enhance biogas production and to supply resistance to significant and rapid $\mathrm{pH}$ changes that might occur in the system.

The $\mathrm{pH}$ profile depicted in Figure 3 shows that during the 50 days of operation, the $\mathrm{pH}$ value slightly decreased during the starting period for 5 days, where the $\mathrm{pH}$ values varied from 6.45-7.3, while after the steady state the $\mathrm{pH}$ value varied from 6.3-7.5. In all the phases, the $\mathrm{pH}$ value dropped during the initial period then tends to move towards neutral again. However, the non-methanogenic microorganisms responsible for hydrolysis and digestion are significantly active at a low $\mathrm{pH}$, while on 
the other hand the methanogenic microorganisms become inactive at the low $\mathrm{pH}$. Furthermore, during hydrolysis and digestion, the organic matter are been converted to soluble compounds and then degraded to acetate, hydrogen, carbon dioxide, propionate and butyrate.

The monitoring of alkalinity is an effective way to ascertain the production of VFA in the digester and is balanced with its consumption (Lettinga \& Pol, 1991; Torkian et al., 2003). This affected the alkalinity to slightly increase and decrease through the period of study. Thus the alkalinity profile (Figure 3) of $1992 \mathrm{mg} / \mathrm{L}, 1802 \mathrm{mg} / \mathrm{L}$ and $2295 \mathrm{mg} / \mathrm{L}$ at the OLR phase change of 3, 7, $10 \mathrm{kgCOD} \cdot \mathrm{m}^{-3} \cdot \mathrm{d}^{-1}$ respectively.

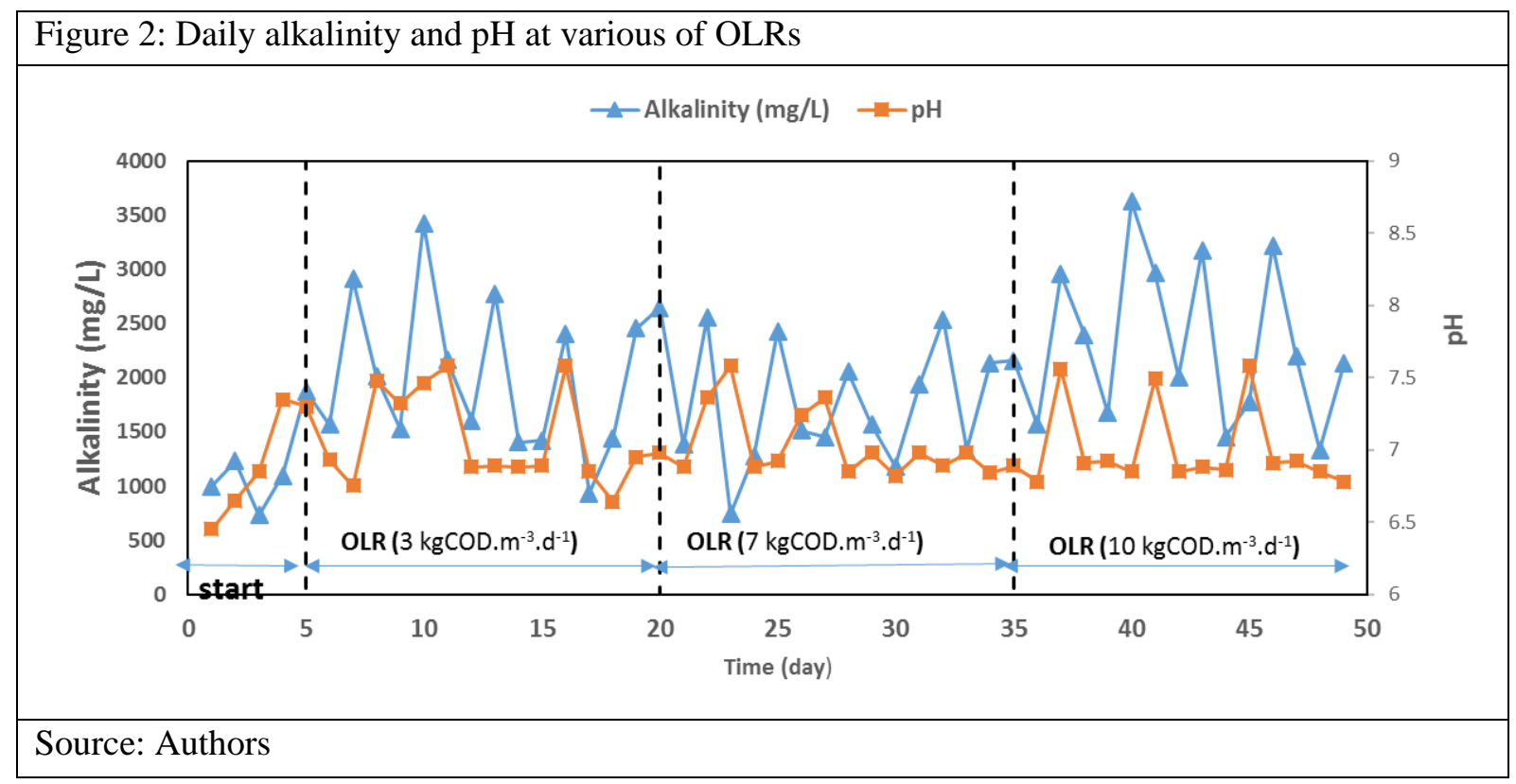

\section{Conclusion}

The effect of HRT and OLR on biogas production was studied by performing an USAB experiment with synthetic slaughterhouse wastewater at a mesophilic temperature. It was established that the yield of biogas production in $\mathrm{AD}$ processes is influenced by both operational and environmental factors. The experimental results in this study demonstrated that a suitable HRT and OLR for the AD process is 12 $\mathrm{h}$ and $7 \mathrm{kgCOD} \cdot \mathrm{m}^{-3} \cdot \mathrm{d}^{-1}$ respectively, likewise, a $\mathrm{pH}$ range of 6.3-7.5 should be used to maximise the biogas production rate and the COD reduction. Although, alkalinity is indispensable as a buffer in an $\mathrm{AD}$ system, overwork of alkaline substrates should be prevented. Otherwise, a $\mathrm{pH}$ balance will likely be uneven. The hypothesis of this study was evaluated, and the constancy of the AD process was successfully maintained in both phases of the study. Therefore, anaerobic digestion of slaughterhouse wastewater is a significant option for the management of organic wastes.

\section{Acknowledgement}

The authors wish to thank the Durban University of Technology and the National Research Foundation (NFR) of South Africa for their support.

\section{Reference}

APHA/AWWA/WEF. (2012). Standard Methods for the Examination of Water and Wastewater. Standard Methods, 541. https://doi.org/ISBN 9780875532356

Bustillo-Lecompte, C. F., \& Mehrvar, M. (2015). Slaughterhouse wastewater characteristics, treatment, and management in the meat processing industry: A review on trends and advances. Journal of Environmental Management, 161, $287-302$. https://doi.org/10.1016/j.jenvman.2015.07.008

Bustillo-Lecompte, C. F., \& Mehrvar, M. (2017). Treatment of actual slaughterhouse wastewater by combined anaerobicaerobic processes for biogas generation and removal of organics and nutrients: An optimization study towards a cleaner production in the meat processing industry. Journal of Cleaner Production, 141, 278-289.

https://doi.org/10.1016/j.jclepro.2016.09.060

Chollom, M. N., Rathilal, S., Pillay, V. L., \& Alfa, D. (2015). The applicability of nanofiltration for the treatment and reuse of textile reactive dye effluent. Water SA, 4l(3), 398-405. https://doi.org/10.4314/wsa.v41i3.12

Dasgupta, J., Sikder, J., Chakraborty, S., Curcio, S., \& Drioli, E. (2015). Remediation of textile effluents by membrane based 
treatment techniques: A state of the art review. Journal of Environmental Management, 147, 55-72. https://doi.org/10.1016/j.jenvman.2014.08.008

Gerbens-Leenes, P. W., Mekonnen, M. M., \& Hoekstra, A. Y. (2013). The water footprint of poultry, pork and beef: A comparative study in different countries and production systems. Water Resources and Industry, 1-2, 25-36. https://doi.org/10.1016/j.wri.2013.03.001

Jha, P., Kana, E. B. G., \& Schmidt, S. (2017). Can artificial neural network and response surface methodology reliably predict hydrogen production and COD removal in an UASB bioreactor? International Journal of Hydrogen Energy, 42(30), 18875-18883. https://doi.org/10.1016/j.ijhydene.2017.06.063

Kweinor Tetteh, E., Muñoz Torre, R., \& Aizpuru, A. (2017). Nitrate recycling from centrate as a strategy to mitigate odour release. Industriales, Escuela D E Ingenierias, (Semestre Internacional).

https://doi.org/http://uvadoc.uva.es/handle/10324/26109

Lettinga, G., \& Pol, H. (1991). UASB Process design for various types of wastewaters. Water Science and Technology, 24(8), 87-107.

Tetteh, E. K., Rathilal, S., \& Chollom, M. N. (2017). Treatment of Industrial Mineral Oil Wastewater - Optimisation of Coagulation Flotation process using Response Surface Methodology (RSM). International Journal of Applied Engineering Research, 12,(23), 13084-13091. Retrieved from ISSN 0973-4562

Tetteh, E. K., Rathilal, S., \& Robinson, K. (2017). Treatment of industrial mineral oil wastewater - effects of coagulant type and dosage. Water Practice and Technology, 12(1), 139-145. https://doi.org/10.2166/wpt.2017.021

Torkian, A., Eqbali, A., \& Hashemian, S. J. (2003). The effect of organic loading rate on the performance of UASB reactor treating slaughterhouse effluent. Resources, Conservation and Recycling, 40(1), 1-11. https://doi.org/10.1016/S09213449(03)00021-1 